\title{
Building Global Leadership to Optimize the Future of Traditional and Alternative Medicine
}

\author{
Phyllis L Maclntyre $^{1 *}$ and Philippe A Souvestre ${ }^{2}$ \\ ${ }^{1}$ Fairleigh Dickinson University, Vancouver Campus, BC V6B2P6, Canada \\ ${ }^{2}$ NeuroKinetics Clinic, Vancouver, BC, V6H 3K2, Canada
}

\begin{abstract}
Health Care professionals are effective problem-solvers in a specific area of technology; leadership calls for a very different way of thinking and learning. Leadership development is a combination of experiential learning and programmed learning, including the conceptual frameworks of leadership, practice to integrate and apply the metacognitive skills of leadership, such as self-discovery of leadership identity and a movement towards mindfulness. Integral to this learning is the support of other leaders who provide a mixture of coaching and mentoring to sustain the new leader's growth. Leadership education takes place beyond university in a context that broadens the career opportunities for health care professionals. In the USA leadership development education has a business focus, while in Canada it values sustainability and a holistic thinking, particularly in medical and applied sciences. Often professionals regard leadership training as a soft skill with less value in their technical field of practice and this presents a challenge for leaders in organizations or professional associations, who need to identify the preferred educational strategies to develop leadership or to risk using leaders without the essential technical expertise for strategic planning and decisionmaking. Employer surveys show an expectation that health care graduates have equivalent skills in technical expertise, business knowledge, and leadership. Learning leadership includes leadership practices to describe and quantify the leadership of individuals and to characterize the leadership of the specific group; secondly, a workshop on leadership education based on transformational learning and thirdly, formation of a community of leaders who advocate and further leadership development.
\end{abstract}

Keywords: Health care professionals; Leadership development; Traditional medicine; Alternative medicine

\section{Introduction}

In mid-September 2016, leading representatives of health care professionals from the five continents came together in Amsterdam for the 6th Annual Conference and Exhibition on Traditional and Alternative Medicine (TAMC 2016). They shared their respective biomedical practices, academic research, clinical and personal experiences regarding innovative, problem-solving approaches in various areas of medicine. Herein referred to as the TAM community, the health care professionals, academics, and researchers voiced and exchanged more specific to and relevant with Traditional and Alternative Medicine (TAM). We were invited to host a panel at TAMC 2016, which turned into an opportunity to observe the leadership development milieu of TAM. Leadership development calls for a very different way of thinking and learning; it reflects a mindset that continues to evolve and it is specific to professional groups and their environment. In the context of TAM, specific influences relate to global leadership and the relevant environmental factors have business and regulatory imperatives. The purpose of this paper is to contribute clarity and make connections between the various understandings of leadership development and recommends how the TAM community might proceed to optimize the future of TAM. The paper describes ways of learning leadership that are relevant and supportive of a community of health care professionals.

What is the direction of medicine and how are advances made? Historically, advances and innovation come through leadership and collaboration among peers. Traditional medicine practiced in larger institutions such as lends itself to identifying areas of challenge, communicating, and collaborating with peers and scientists to improve the patient experience. Larger organizations recognize that leaders are necessary to manage the inherent complexity of the environment in which health care professionals operate. Alternative medicine practices and traditional private practices tend to be relatively small with 1 to 5 employees. In these small settings leadership is not highlighted; but it is still very necessary, especially in regards to helping to direct and grow the future of alternative medicine. Leadership skills enable health care professionals to manoeuvre and navigate in an increasingly ambiguous environment [1-5]. We review approaches to leadership development and explain how they can benefit healthcare professionals in the TAM community. We share how leadership skills are evident within the TAM community, and discuss some examples of how current thinking blends medical techniques from both Western medical physiology and acupuncture practices to treat many conditions that are not feasible through a single medical modality. Health care professionals are effective problem-solvers in their specialties; yet leadership requires a different combination of skills and a global mindset that is comfortable with change.

Through listening to the presentations at the conference, we learned about the mature research and expertise within the TAM community and it was evident that leaders were present. In this biomedical milieu, we observed several ways to perceive the nature of leadership During the conference, we gained an appreciation of the diversity of the TAM community through interaction and speaking in person with most

*Corresponding author: Phyllis L MacIntyre, Fairleigh Dickinson University, Vancouver Campus, BC V6B2P6, Canada, Tel: +6046484490; E-mail pmacinty@fdu.edu

Received December 31, 2016; Accepted January 23, 2017; Published January 27,2017

Citation: Maclntyre PL, Souvestre PA (2017) Building Global Leadership to Optimize the Future of Traditional and Alternative Medicine. J Health Educ Res Dev 5: 208. doi: 10.4172/2380-5439.1000208

Copyright: (c) 2017 Maclntyre PL, et al. This is an open-access article distributed under the terms of the Creative Commons Attribution License, which permits unrestricted use, distribution, and reproduction in any medium, provided the original author and source are credited. 
of the attendees. They came from very different areas of the globe, brought a wide range of healthcare practices and distinctive training orientations. Readily evident was the potential for leadership within the TAM community. We learned about this global health care community as the members' presentations demonstrated thorough, research skills and documentation of their clinical studies and reports. In the TAM community, global leadership development is nascent and the practice of its health care professionals is sufficiently varied that this paper limits its focus to leadership development. By way of example, consider the global practice of Traditional Chinese Medicine in contrast to the Kampo medicine of Japan; the first is widely known, while the second is limited to Japan. We approach the subject of leadership development for these health care professionals in the global context; to explore the ability to lead in a variety of cultural contexts, both globally and locally, and in ways that honour diversity.

\section{The Emergence of Global Leadership}

In the late twentieth century, the business environment in most of the world became more dynamic as new technology, economics, and political changes forced business, government, and health organizations to deliver service differently. Globalization provided the impetus for change in the Western world; it began in 1980s and was critical to opening new markets and forcing established players to compete in different ways with the new entrants, and dramatically changing business organizations. In North America, many corporations were unprepared for the sweeping change and stumbled through massive downsizing of organizational structures to adapt to the new reality of global business. The dismantling of the USSR opened new markets for Russia and Eastern Europe, who became major players in global energy markets and a source of talent in mathematics, computer science, and medicine. Technological change had a considerable impact on traditional organizational structures, where the manager's role primarily related primarily to coordination across functions and businesses. Personal computers, networking innovations, and the cell phone enabled paperless communication and changed structures by eliminating layers of management in corporations and government services. Industry structures changed as technology enhanced manufacturing the global supply-chain evolved, and call center technology shifted most customer service to Asian countries. Owners, political leaders, and executive managers began to identify competencies as one ingredient to connecting individual performance to the ability to adapt to the frequency of change. This included a stronger focus on the future and a watchful eye on a broader range of strategic factors, both within and outside of the organizational system. It was evident that managing in the global context required adaptability and flexibility, and the ability to lead change was the impetus for implementing leadership development. Avolio used a graphic to illustrate an implementation process for leadership development in the later twentieth century [6-8]: Quinn, Anderson and Finkelstein's Graphic of the Leadership Development Cycle (1996) (Figure 1).

In health care environments, new technology increases the requirements for professional development programs; these are critical to support health care professionals in the adoption of innovation and new practices. This is particularly relevant to professionals working in private or independent practice. In most professions, such as law, engineering, nursing, and teaching, professionals retain expertise through a combination of licensing and regulatory mandates that are unique to their state or country. Technical expertise is the easiest to recognize and reward in a profession and programs for updating technical expertise take priority. Around the globe, the Internet empowers patients with a vast array of information and raises their expectations of health service, specifically in the non-public delivery of health care. For example, the ability to book or pay online for health care services changed the business of health clinics with implications for stakeholders like health benefits providers, patient funding sources, health regulators, and the business tax systems. A broader range of stakeholders now participate in the interaction between the patient and the health care professional. When an injured Dutch policeman flies to Canada to receive an innovative health care service, the clinic leader takes responsibility to deliver the medical care and manage the cross-cultural business transactions on behalf of the patient. For the clinic to market and deliver services globally, the clinic's health care professionals are competent leaders in their technical area of practice and in global business.

Advancements in the application of learning and curriculum development combined to provide ways of learning leadership that accelerate leadership development. Formal education provides the leader access to the theory and practice of leadership in existing management and leadership education programs. Often the missing elements of leadership development are access to the facilitated learning and the group learning that enhances visioning and relationship building, particularly in community with other professionals. Relevant to learning leadership skills is the distinction made between leadership and management; even though new definitions and interpretations prevail; the literature reveals an intricate entanglement of terminology [7]. Managers and leaders both acquire and manipulate capital, human resources, intellectual capital, and the tangible assets of property, equipment, and computing power. Managers focus on the current, present operations while leaders view a longer time horizon, have a stronger focus on the future, and have a visioning capability $[9,10]$. The history of management education provides a roadmap of curriculum development that demonstrates how to combine highly technical and analytical content into new ways of learning management and leadership $[7,11]$. As health care professionals consider ways to integrate leadership development into their growth, we recommend review of the history of learning leadership in business education as a useful preliminary [12]. Our definition of global leadership draws upon the program development done by Rowe et al. whose competency framework for a master's degree in global leadership included the following [13]:

(A) Personal Leadership Working in a Global Context

- Self-Reflective Practice

- Resilience and personal Adaptability

- Self-in systems Management Capability

(B) Leading in a Diverse Global Contact

- Culture-General and Culture-Specific Knowledge

- Intercultural Interaction and Communication

- Intercultural Group Facilitation

(C) Leading Sustained Change in Complex Environments

- Knowledge of Global Political, Social, and Economic Issues

- Knowledge if International Organization Systems and Change Strategies

- Capability to Lead Change in Complex Environments 


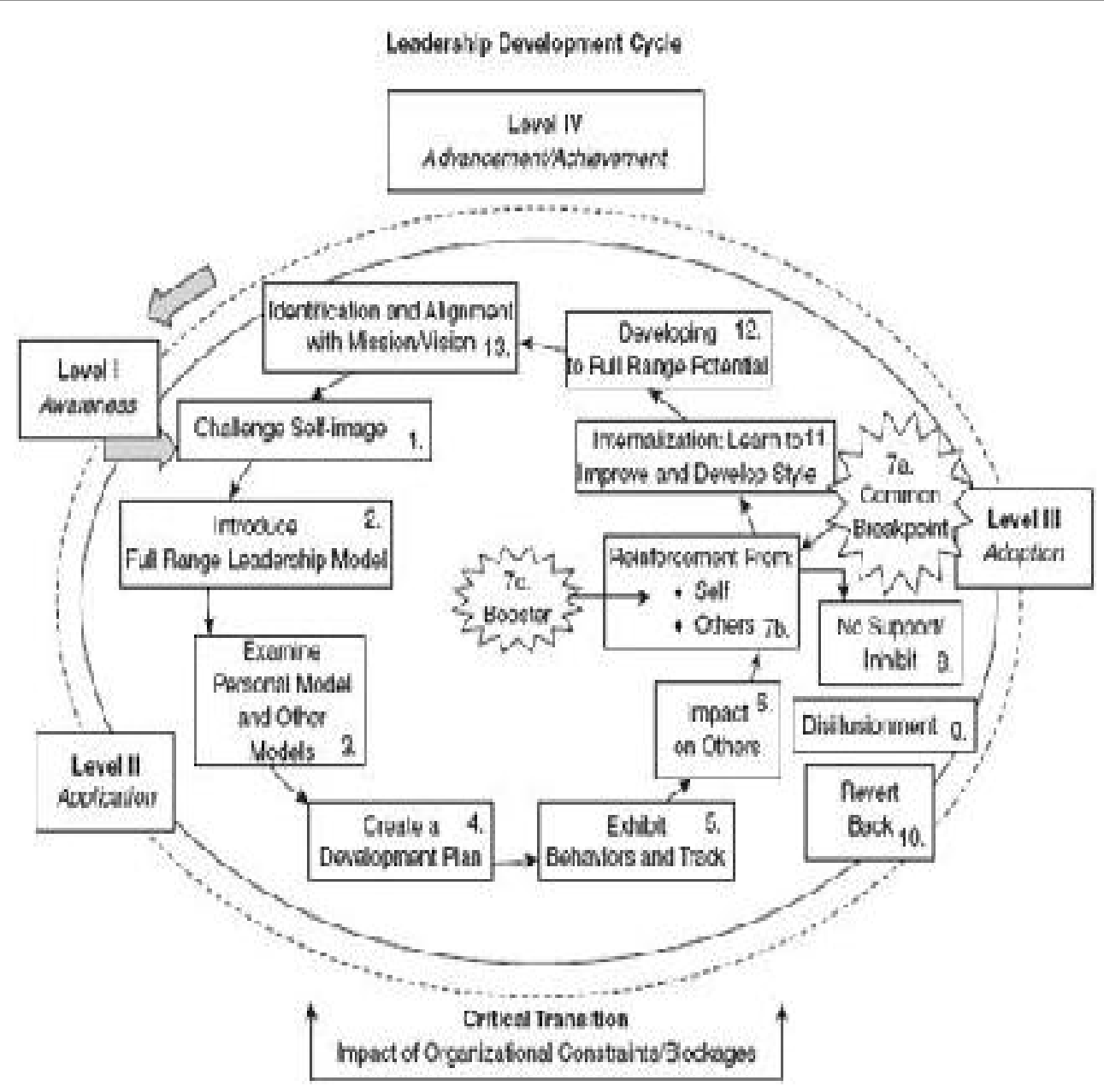

Figure 1: Quinn, Anderson and Finkelstein's graphic of the leadership development cycle (1996).

Rowe et al. offered a glimpse at the development process for an educational program in global leadership; they concluded it was a challenging endeavour, one requiring collaboration and guidance from a Consultative Committee. We suggest this experience provides the TAM community with yet another source for their exploration of leadership development; Rowe et al. reinforced these authors' evidence that each community of professionals needs to design their leadership development initiatives to address a the most relevant range of professional and environmental factors.

Foundational to the understanding of global leadership is the recognition that leadership is a process, not an outcome or product of attending an educational program. Rather, it is a continuous process of transforming oneself and others, while learning to identify situational factors and adapt to multiple roles. Leaders evolve through a combination of experience, learning, and behavioural change; and learning to lead requires recognition of the developmental nature of leadership and attention to the relationships between leaders and followers [6]. The emphasis on relationship building originates from the concept of transformational leadership and the dual roles of leaders and followers, who move in alignment intellectually and with a common moral purpose;) Bass showed an association between a leader's moral values and the full range, transformational leadership style $[8,14-17]$. This contributed to learning leadership in new ways; and organizations began to train and develop for different leadership skills and competencies. Learning to lead began to place more emphasis on areas like reflective practice, professional conversations, and building community. Staying informed of developments in areas of medicine is more challenging than in the past and this makes learning how to adapt to change as one way to help shape the future of medicine. The dynamics of health care change redefine the competencies of health care professionals to pursue development that enables them to adapt, work collaboratively across technical disciplines and cultures [18].

\section{Leadership Development}

Leadership is about building relationships and the ability of the leader to influence change in others, whether he or she is leading a team, an organization, or a medical practice. Global leadership development requires a program of planned learning, designed for global contexts in ways that enhance the leader's ability to navigate cross-cultural situations [13]. Leadership development programs commonly include learning current concepts and frameworks of leadership plus inclusion of experiential learning to integrate and apply the higher level or meta-cognitive skills, such as self-discovery and shared reflection. The prefix "meta" indicates a higher level of thinking, intended to develop the leader's skills and abilities in areas like self-knowledge, emotional resilience, and personal drive [19]. Bird and Stevens identified three sub-dimensions of meta-cognitive skills specific to cross cultural intelligence: awareness, planning, and checking. Awareness is the 
leader's ability to assess his or her sensitivity to a situation; planning includes the anticipation and preparation anticipates and prepares for leading the situation; and checking is the leader's ability to monitor his behaviour and actions for consistency with his plan [20].

Kaagan defined leadership development as the process of teaching leadership and suggested a mix of learning activities that promoted a safe, shared, adult learning experience [21]. He taught leadership that began with substantive learning of leadership theory followed by applied practice through a curriculum of learning activities. The learning activities integrated model of reflection-in-action, introducing professionals to tools for learning more disciplined thinking through reflection and inquiry [22]. By teaching leaders to use these skills, they learned to pause and examine their assumptions, reflect on individual experience, share, and test their assumptions with others, and reconstruct the experience in a future situation [23,24]; This process of critiquing and re-examining introduces a leader to an examination of situational factors and draws upon the multiple perspectives of others to develop different ways of thinking about his roles as a leader. This practice shows the integration of the transformational leadership style and that the leader's reflection involves all members of a team because it connects leaders to the experience of other leaders, and to the creation of a community [25-35].

Integral to learning leadership is the support of experienced leaders, whose roles include both coaching and mentoring to enable leaders' development and growth. In many professions, learning to lead encompasses both formal education and practice in a vibrant practice field that contributes to a professional culture that values leadership development. Ideally, the profession acknowledges the importance of leadership development and forms communities of learning and practice to nurture and sustain a professional culture that values leaders. Other essential leadership skills include communicating a commitment to the growth of new leaders and a willingness to challenge the status quo by speaking up and asking questions about the reasons for change [34]. Skills in leadership development include envisioning the future, the ability to work in a team, and the ability to teach and learn from followers. Leadership involves multiple roles of leading and following, of cooperation and collaboration, and of mediation and conflict resolution [36]. For professionals working in a health care system, all efforts are collective and intended to inspire and exceed the expectations of patients $[18,37]$. By learning the leadership skills to communicate and interact more effectively with their patients and colleagues, health care professionals enhance their leadership and contribute to growth of a community of likeminded individuals.

Skill development for new leaders includes learning how to communicate through dialogue and professional conversations. Sloan referred to the inclusion of dialogue [38] in the learning process for professionals because they practice communicating credible and legitimate perspectives that inform the views of all listeners. D’Arix and Kouzes and Posner reinforced the importance of the leader's credibility which is earned only through the leader's actions and behaviour [29]. Instruction that enables leaders to accelerate their learning of conversational skills includes executive coaching, and mentoring programs, which matches experienced leaders with new or emerging leaders in the profession [39,40]. In the 1990s, executive coaching provided a teaching approach for leaders to explore and experiment their reality and begin their reflective practice and leadership behaviour with the aid of facilitated learning [41]. Canadian researchers, [42], used an apprenticeship model to describe a leadership development approach that combined formal and informal education through an experiential, adult learning scaffold. Guiding the apprentice's learning were artisans, mentors, and adequate practice time to refine the new leader's skills. The apprentice model focuses on learning a craft and provides a suitable model for the developmental journey of a leader. A graphic representation of this apprenticeship model of leadership is shown in Figure 2 Optimal Program Design for Leadership Development. In an organizational context of business or government, a struggle emerges with respect to the choices for succession planning and how to combine the technical expertise with business thinking for the future success of the organization [43]. This presents a challenge to the senior leaders, who wrestle with the dilemma of choosing the preferred educational strategies to develop leaders for succession. Lessons learned in business education and in the applied sciences offer insights for the health care milieu of TAM. When leaders learn competencies in global leadership, they are more likely to remain with an organization and contribute strategically to the growth of the organization. Themes are also important in leadership development programs because they reflect the accumulated values that contribute to the legacy of a profession or an organization [2]. In other words, the values and beliefs of the TAM community need to resonate in the choices made for leadership development programs and initiatives.

Leadership development is a process that takes place over a period of years; it is a continuous process, requiring attention to the leader's context, the country in which he practices and the forces of change that will influence the growth of the health care practice. Leadership education is the combination of learning and development that fosters and supports the leader's growth and the design of the educational program is specific to a target population or cohort of leaders. In Canada, Henein and Morissette described leadership education as an invisible field of study with a lack of leadership education and developmental pathways for leaders [42]. In a global community like TAM, one remedy is to initiate programs for leadership development that coincide with the annual conferences. This approach is particularly significant for professionals who operate in independent, private practice and look to the annual conference for an opportunity to share their knowledge and practices and network with members of the community. In a professional community that is global, members initially look to their local leaders for guidance and direction; and this was observable in the TAM community during the conference in Amsterdam.

In the US, nursing education was the first profession to integrate leadership development into the undergraduate university curriculum

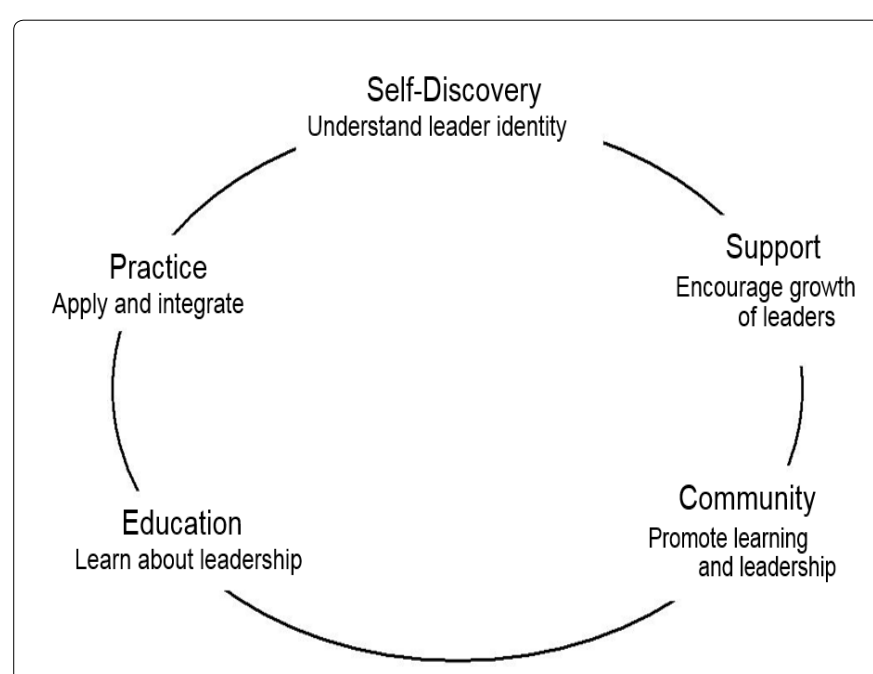

Figure 2: Optimal programme design for leadership development. 
[44]. In Canada, Kilty reviewed programs for nursing leadership development and she found a vibrant culture for learning leadership within the profession. Throughout the country, nursing leadership development programs were available through nursing associations, union sponsored programs, educational institutes, and nursing centers, and in university nursing programs. Internationally, nursing leadership development programs existed in Australia, Sweden, the US, and the UK. One impressive initiative was known as Leadership for Change (LFC) and involved 50 countries in the Caribbean, in Latin America, in the south Pacific, in East, Central and southern Africa and in Southeast Asia. LFC used an action-learning approach for nurse leaders and potential leaders; and the program design included five interrelated components: workshops, individual development planning, team projects, structured learning activities between workshops, and mentoring. These program components were adapted to meet differing requirements of the host countries. By attending the LFC program, nursing professionals learned how to address the changing health care policy within their countries and, at the same time, how to adapt to global health care practice. Lilly produced a template for nursing leadership development, which indicates the advanced nature of leadership development in the nursing profession. See Figure 3 Graphic of Nursing Leadership Development. Another example of a profession that incorporated learning leadership into university programs for the profession of engineering, MacIntyre proposed a framework for learning leadership in engineering education [45], see the Figure 4 Conceptual Framework for Learning Leadership.

In the medical practice of physicians is an awareness about the differences between medicine and leadership. Barnhart characterizes the role of the physician leader as the "physician whiplash"; that is, success as a physician is completely contrary to success as a leader [46]. The author shows how medicine became more team based and the necessity of the physician to adapt by learning leadership skills in teamwork, cross-disciplinary collaboration, and a future orientation. The tension for the physician leader is comparable to that of business leaders, nursing leaders, and educational leaders who wrestle with letting go of their expertise. Another way of expressing this tension is developing the courage to lead without the contingency of owning the knowledge; leaders who learn to let go of the technical expertise and shift focus to leading or the only professional who can resolve the health issue. See Table 1, A table on the contrasting roles of a physician between traditional medical doctor and leader. Programs for leadership development require a combination of experiential learning and programmed learning, including understanding the history of leadership education and practicing skills in a way that helps the leaders integrate meta-cognitive skills. Meta-cognitive skills refer to thinking about how one is thinking; it's focus is on learning how to lead through examination of one's inner before attempting to lead others.

Self-discovery through reflective practice initiates meta-cognitive thinking; and as the leader evolves, reflective practice may achieve mindfulness $[19,47]$. Self-discovery contributes to increasing a new leader's self-awareness and it is a learned practice. An integral part of this learning experience is the support of other leaders in the profession, who provide a mixture of advocacy, coaching, and mentoring to sustain the new leader's growth. Mentoring relies on a supportive community of experienced leaders who willingly invest their time to share knowledge, and experience through leadership stories [48].

By the twenty-first century, leadership emphasized growth through collaboration and leading with a clear alignment between the leader's vision, moral focus, and ethical behaviour [34,49]. Advancements in new ways of learning and integration of courses on leadership programs proved to accelerate leadership development in business, schools, post-secondary education, and in nursing. Formal education includes delivery of university based management and leadership programs; they provide access to leadership theory, models and frameworks, and the history of exemplary political and business leaders. Usually, the missing elements of leadership development in formal education are access to the facilitated learning and the group learning that enhances visioning and relationship building. According to Ely and Rhode leadership development is a combination of learning conceptual frameworks of leadership, practice to integrate and apply the skills of leadership, selfdiscovery of one's leadership identity, and support through coaching and mentoring to sustain the leader's growth. Learning to lead in new ways evolved quickly and enabled leaders in many professions to emerge and grow.

\section{Reflective Practice}

Reflective practice is self-exploration, an examination of one's beliefs and values and questioning the assumptions and reasoning behind one's actions and behaviour. Use of reflective practice began with [22] work on teaching business professionals how to reflect and remains a seminal work in management education. Brookfield integrated reflective practice into education for new teachers and claimed that the teachers improved their ability to facilitate student learning [50]. Densten and Gray stressed the importance of integrating reflective practice into learning leadership to help leaders connect leadership theory to their experience of leadership [51]. Cunliffe went beyond self-reflection to emphasize critical thinking and taught leadership using a philosopher's metaphor of three intertwining threads including relational leadership, moral activity, and reflexivity [52]. Reflexivity incorporates reflection through conversations, a means of questioning accepted assumptions and behaviour in business decision-making through open dialogue among group members. Relational leadership builds on social learning, in the recognition that leaders exist only in the context of their relationships with followers, emphasizing the leader's role cannot exist in isolation of his followers. Cunliffe's inclusion of moral activity might be a response to the corporate scandals and unethical behaviour of the first decade of the twenty-first century in the US and the UK [52]. Her research deepened understanding of how to teach leadership, with attention to strengthening the leader's ability to develop relationships and lead with a moral purpose.

\section{Professional Conversations}

In Scotland, Alexandrou et al. identified professional conversations as the mechanism for teacher leaders to move from their private reflection, to dialogue, and to public exchange in their field of practice [2]. Leaders whose career pathway is in a corporate, health, or government setting are more likely to learn professional conversations as part of in-house training and executive coaching services, or through executive management programs $[41,38,53]$. The key benefit of learning how to engage in a professional conversation is an accelerated leadership development; and for leaders whose post-secondary education is in education or applied sciences, executive coaching teaches them conversational skills, preparing them for the multifaceted demands of leading others [1]. Research on leadership and coaching is more substantive from academics in physician and nursing education [54,55], in psychology [56-58], and in women's leadership development [59], and provided extensive literature on the pedagogy of leadership. New ways of teaching leadership emerged as group learning replaced individual reflective practice and leaders were taught relational 


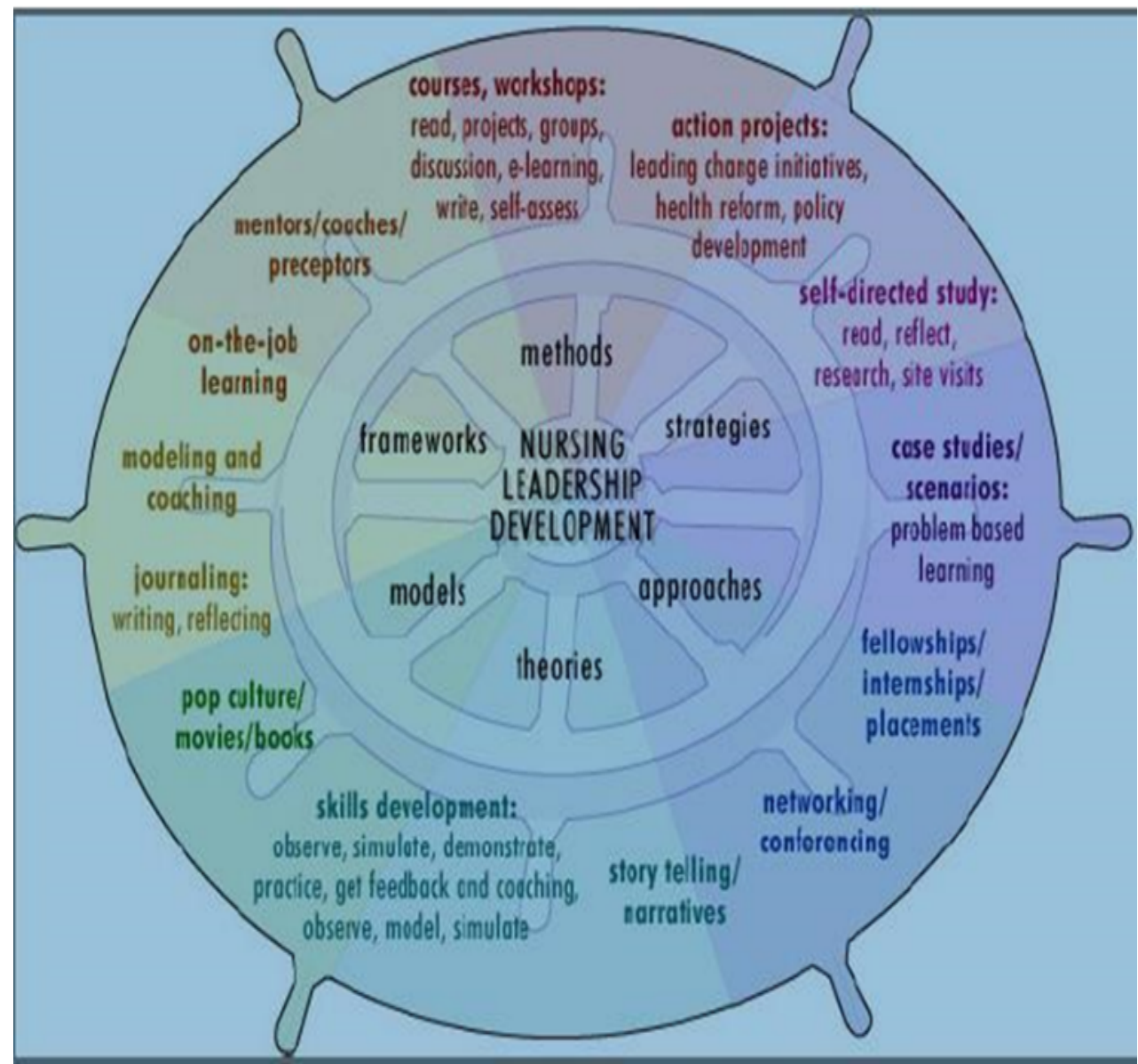

Figure 3: Graphic for nursing leadership development.

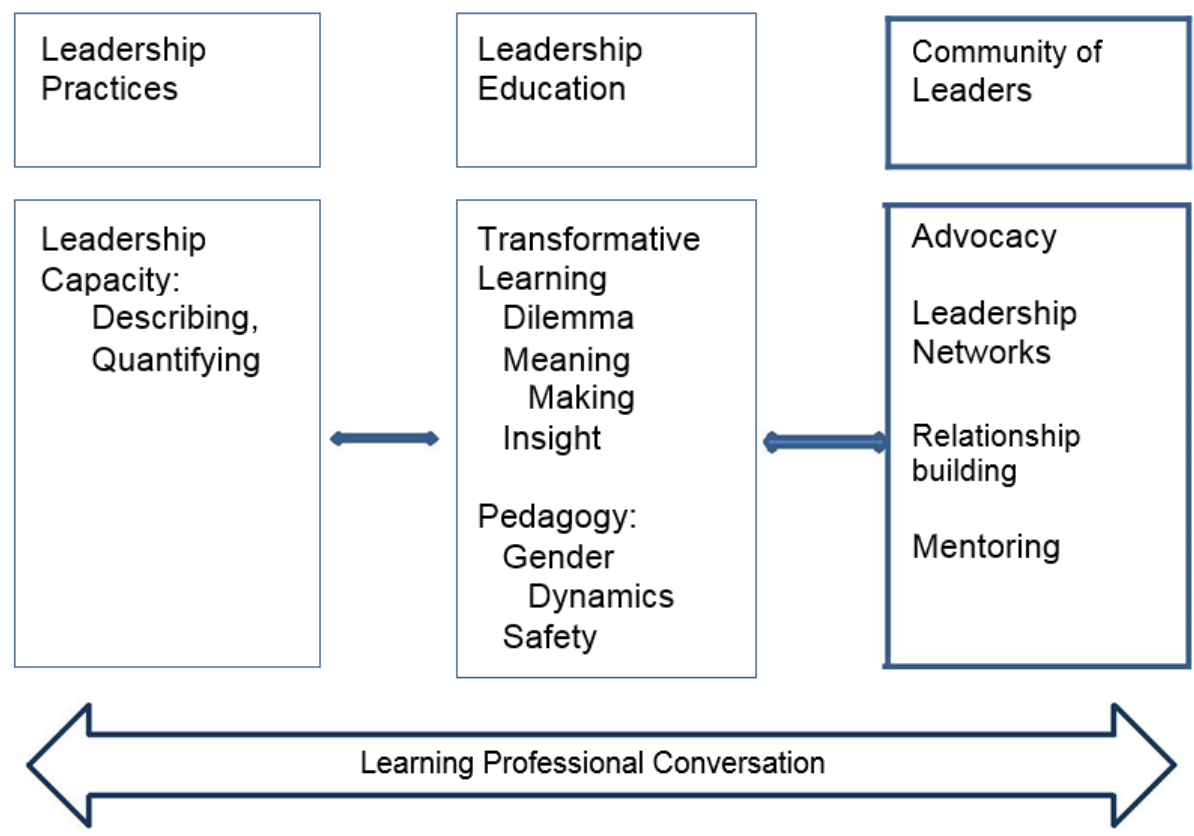

Figure 4: Conceptual framework for learning leadership [45]. 


\begin{tabular}{|c|c|}
\hline The Nature of Medicine & The Nature of Leadership \\
\hline Prescribe and expect compliance & Lead, influence and collaborate \\
\hline $\begin{array}{c}\text { Immediate and short-term focus and } \\
\text { results }\end{array}$ & $\begin{array}{l}\text { Short-, medium- and long-term focus } \\
\text { and results }\end{array}$ \\
\hline Procedures/episodes & Complex processes over time \\
\hline Relatively well-defined problems & III-defined, messy problems \\
\hline Individual or small-team focus & $\begin{array}{l}\text { Larger groups crossing many } \\
\text { boundaries, integrated approach }\end{array}$ \\
\hline $\begin{array}{l}\text { Being the expert and carrying the } \\
\text { responsibility }\end{array}$ & $\begin{array}{l}\text { Being one of many experts and sharing } \\
\text { the responsibility }\end{array}$ \\
\hline Receiving lots of thanks & Encountering lots of resistance \\
\hline Respect and trust of colleagues & Suspicion of being a "suit" \\
\hline
\end{tabular}

Table 1: A table on the contrasting roles of a physician between traditional medica doctor and leader [46].

leadership [52]. As noted by Garcia, the leader's thinking is incomplete unless it incorporates dialogue and reflection with others [55]. Leaders require a practice field for shared reflection, experience, and deliberate learning. In the organizational context, Garciass approach suggested a practice field for the woman engineer leader that expands critical thinking to a wider range of issues related to the organization's culture and its social responsibility [55]. These critical skills can be learned through coaching and mentoring, which generate the professional conversations on her leadership.

\section{Community}

In the context of learning leadership, it is well known that interaction between leaders provides trigger events for leadership development [6]. When a senior leader acknowledges the leadership qualities of an emerging leader, she leaves the meeting feeling validated as a leader. This is an example of a positive trigger event that contributes to leadership development through role modelling and positive reinforcement; and the outcome is that both grow as leaders. Learning leadership necessitates a community of practice where leaders converse and share what they learned in their actions as leaders. Community of practice is metaphor for a learning process that is socially constructed, interactive, and conversational. The intent is to open a learning space that enables leaders to share tacit knowledge and move towards a vision of leadership for the profession. Coordination of formal and informal learning takes place through networking, mentoring, coaching, and learning conversations [2]. The purpose of this community is to create a culture of leadership development in which professionals articulate, share, and learn leadership. Building on a capacity for shared learning, the leaders begin an incremental movement to define the most relevant dimensions and context for their community $[13,60,61]$ reinforced the proactive responsibilities of senior leaders to develop leaders by investing time to sponsor and promote inclusive leadership development. Like the intricacies of management education versus leadership education, leadership development requires a combination of learning that is transformational, contextual, and experiential. As noted by Garcia, the leader's thinking is incomplete unless it incorporates dialogue and reflection with others [55]. Leaders require a practice field for shared reflection, experience, and deliberate learning; this is the purpose of community.

\section{Leadership Practices}

The Leadership Practices Inventory (LPI) is a self-assessment tool for a new leader with a starting point for leadership development; the results of the LPI help the new leader to gain a picture of his current leadership strengths. Completing a self-assessment and reflecting on the results is an experiential learning activity. Leadership philosophy begins with a focus on the strengths of the leader and provides both positive and generative beginning. The purpose of self-assessment is to quantify and describe the leader's behaviour, giving the professional a view of herself in the context of leadership and providing a source of information for reflection.

We use the leadership practices inventory, the LPI-Self, to describe and quantify the leadership capacity of health care professionals; and herein refer to it as the LPI. Kouzes and Posner [29] developed the model, known as the leadership challenge, from research on personalbest experiences of leadership. Kouzes and Posner developed the LPI to reflect the transformational leadership of accomplished leaders and evidence continues to support their claims [27]. The LPI organizes behavioural statements of successful leaders into five leadership practices; and the authors claim leadership is a learned behaviour developed through study of the five practices. The inventory includes thirty statements of behaviour and actions that are rated on a 10 point Likert scale with statements grouped into five leadership practices or subscales: "modelling the way" by role modelling, and affirming shared values; "inspire a shared vision" by visualizing the future through a visioning process involving all stakeholders; "challenge the process" through fostering risks, innovative ways of improvement by reflecting on experiences; "enable others to act" through creation of learning processes and building trusting relationships; and "encourage the heart" by demonstrating appreciation, celebrating the values and achievements of teams [33]. In addition, Kouzes and Posner created another leadership assessment tool that includes feedback from a leader's peers, subordinates, and senior leaders and it is known as the LPI-Observer. Feedback is an essential competency for leaders and a feedback tool like the LPI-Observer provides input for a leader to identify and plan for his leadership development.

The reliability of the LPI was measured by the internal consistency of the participant's ratings of the 30 statements of leadership behaviour that summed to form the total score for the five subscales. Cronbach alpha reliability was conducted on each of the sub-scales. Acceptable reliability $(\alpha>0.70)$ was found for inspire a shared vision, enabling others to act, and encouraging the heart. Challenge the process had questionable reliability $(\alpha>0.60)$ while unacceptable reliability $(\alpha<0.60)$ was found for modelling the way. Kouzes and Posner identified face validity of the LPI as accounting for most of the validity, due to the subjective evaluation of the LPI by leaders who participated previously in the authors' research [27]. The authors reported that participants identified with the language of leadership used in the thirty statements of the LPI. The language or vocabulary described the personal best experience of their own or another leader's; this contributed to the conclusion that the LPI had face validity. Other measures of the validity of the LPI included the statistical measure of factor analysis to support the discriminatory validity of the LPI [62-64]. Vito and Higgins used factor analysis to test the construct validity of the LPI for use by a specific group of police managers [65]. They found the LPI was valid for police leadership performance and a valid construct for assessing the leadership capabilities in law enforcement agencies.

The LPI is a psychometrically evaluated instrument [26,27,62]. It has proven construct validity for groups in nursing, teaching, educational leadership, and law enforcement, despite significant changes in the business environment over the past decades [65-70]. Research on the leadership practices for a sample of Canadian women engineers revealed an ease with valuing relationships across cultures, disciplines, and the many domains business, health, and government that engineering touches [45]. Enable others to act was their dominant 
leadership practice; strength in this leadership practice indicates a collaborative style of interaction and engagement, a reliance on trust and commitment, and respectful behaviour to their followers. Leadership actions that enhances relationships between leaders and followers includes active listening, attention to diverse perspectives, and support for decisions made by followers. The results for the group of women engineers also revealed their comfort with strengthening their followers' capability, including followers' aspirations for leadership, which is a significant role of a transformational leader [71].

Waite, McKinney et al. used a student's version of the LPI to assess leadership skills in a cohort of undergraduate health care students in an interdisciplinary 9-month leadership program at a private, American university [18]. The program design included three consecutive terms. In the first, students engaged in self-examination by questioning their beliefs, values, reliance on power structures, sensibilities to diversity, and personal experiences that influence their thoughts and actions. This learning process deepened their self-awareness and enabled them to articulate a leadership philosophy. In the second term, students explored group dynamics by assessing their behaviour in teams and how well they communicated, resolved conflict, and planned. By addressing topics like prejudice, privilege, stereotyping, social identity, oppression, and personality they began to assess capacity for leading. In the third term, students addressed the community roles of leaders through the lens of social justice; they explored the social determinants of health, sources of power and inequalities, and the power of community to organize and promote health. Teaching or pedagogical strategies that facilitated the leadership learning included reflective exercises, leadership briefs, group debates, engaging guests and panel speakers, individual and team projects, service learning projects, diversity and privilege exercise, fishbowl activities, cultural autobiography, mind mapping, and action learning projects [18]. For the educators who designed this 9-month leadership development program, they realized students entered the health care environment better able to function on diverse, interdisciplinary teams and more confident about leadership roles at the beginning of their professional careers [71-102].

\section{Conclusions and Recommendations}

The authors' approach to leadership development is guided the beliefs that the proof of successful global leadership resides in achievement of measurable improvements in health outcomes. In the short-term, measures include a comparison of the use of a health care service from one period to another; or changes in the knowledge, attitudes, and receptivity of the health care services by a patent or client group. The content of a leadership development program includes designed learning for reflective practice, professional conversations, and building community [102-121]. Learning leadership includes leadership practices to describe and quantify the leadership of individuals and to characterize the leadership of the TAM community; secondly, leadership education requires attention to design of leadership experiences that resonate and build confidence to lead; and thirdly, formation of a community of leaders who advocate and further leadership development. Defining expected outcomes of the leadership development program for TAM requires input from the members themselves and this depends upon the challenges that are both within the local practice and the external forces imposing change on the health care systems. As suggested in this paper, the TAM community should consider planning for leadership development by forming a consultative team and articulating a vision of leadership for the health care professionals in TAM [122-131]. Preliminary questions for members of the community to consider as they explore initiatives for leadership development are the following:
- What defines global leadership in traditional and alternative health care?

- What are the characteristics of a global leader in TAM?

- Why is global leadership important to health care practice?

As progress moves to program design, endeavour to connect leadership development content to the context of the health care professional's work environment, with specific attention to the crosscultural issues of global, health care business. This paper reviewed literature and cited practical applications and examples in global leadership, leadership development, and leadership practices with the intention of exposing conference attendees to the possibilities of leadership development in the TAM community. Ultimately, the measurement of the results of the global leadership development program are the changes in health service delivery, such as increase in the number of patients or improved quality of service.

\section{References}

1. Adams R, Evangelou D, English L, Figueiredo AD, Mousoulides N, et al. (2011) Multiple perspectives on engaging future engineers. Journal of Engineering Education 100: 48-88.

2. Alexandrou ASS, MacBeath J (2014) Scottish teacher leaders: Two accidental journeys enacting leadership for learning. Teacher leadership and professional development. Scotland.

3. Amabile T, Kramer S (2011) The progress principle: Using small wins to ignite joy, engagement, and creativity at work. Harvard Business Press.

4. Amabile TM, Kramer SJ (2011) The power of small wins. Harvard Business Review 89: 70-80.

5. Angood P, Birk S (2014) The value of physician leadership. Physician Exec 40: 6-20.

6. Avolio BJ (2005) Leadership development in balance: Made/born. Psychology press.

7. Avolio BJ (2010) Full range leadership development. Sage.

8. Bass BM, Avolio BJ (1994) Improving organizational effectiveness through transformational leadership. Thousand Oaks, CA: Sage Publications.

9. Thomas D, Stahl GK, Ravlin E, Poelmans S, Pekerti A, (2008) Cultural intelligence. International Journal of Cross Cultural Management 8: 123-143.

10. Thomas H, Carnall C (2008) Leadership development: integration in context Strategic Change 17: 193-206.

11. Mintzberg H (2004) Managers, not MBAs: A hard look at the soft practice of managing and management development. Berrett-Koehler Publishers.

12. Datar SM, Garvin DA, Cullen PG (2010) Rethinking the MBA. Business Education at a Crossroads.

13. Rowe WE, Heykoop C, Etmanski C (2015) A master's degree in global leadership: A story of development pp 187-208.

14. Bass BM, Riggio RE (2006) Transformational leadership. Psychology press.

15. Bass BM (1998) Transformational leadership: Industrial, military, and educational impact. Mahwah, NJ: Lawrence Erlbaum Associates, Inc.

16. Bass BM, Steidlmeier P (1999) Ethics, character, and authentic transformational leadership behavior. The leadership quarterly 10: 181-217.

17. McKinney NS, Waite R (2016) Leadership Development Among a Cohort of Undergraduate Interdisciplinary Students in the Health Professions. Journal of Leadership Education 15

18. Buckley F, Monks K (2008) Responding to managers' learning needs in an edge-of-chaos environment: Insights from Ireland. Journal of Management Education 32: 146-163

19. Bird A, Stevens MJ (2008) Assessing global leadership competencies. Global leadership. Research, practice and development, pp: 64-81.

20. Kaagan SS (1998) Leadership games: Experiential learning for organizational development. Sage Publications, Chicago, USA. 
Citation: MacIntyre PL, Souvestre PA (2017) Building Global Leadership to Optimize the Future of Traditional and Alternative Medicine. J Health Educ Res Dev 5: 208. doi: 10.4172/2380-5439.1000208

Page 9 of 11

21. Schon DA, DeSanctis V (1986) The reflective practitioner: How professionals think in action. 34: 29-30

22. Bolman LG, Deal TE (2003) Reframing Organizations. San Francisco, CA USA: lossey-Bass.

23. Senge PM, Kleiner A, Roberts C, Ross RB, Smith BJ (1994) The Fifth Discipline Fieldbook: Strategies and tools for building a learning organization. New York, USA.

24. Kouzes JM, Posner BZ (2006) The leadership challenge. John Wiley \& Sons.

25. Posner BZ, Kouzes JM (1993) Psychometric properties of the leadership practices inventory-updated. Educational and psychological measurement 53 : 191-199.

26. Kouzes JM, Posner BZ (2002) The leadership practices inventory: Theory and evidence behind the five practices of exemplary leaders.

27. Kouzes JM, Posner BZ (2011) Credibility: How leaders gain and lose it, why people demand it. John Wiley \& Sons.

28. Kouzes JM, Posner BZ (2011) The Leadership Challenge. San Francisco, CA: Jossey-Bass.

29. Kouzes JM, Posner BZ (2010) The five practices of exemplary leadership. John Wiley \& Sons, p: 237

30. Kouzes JM, Posner BZ (2003) The Leadership Practices Inventory (LPI): Participant's Workbook. John Wiley \& Sons, p: 47.

31. Kouzes JM, Posner BZ (2011) The Five Practices of Exemplary Leadership: Non-Profit. San Francisco.

32. Kouzes JM, Posner BZ (2013) Leadership Practices Inventory (LPI) 4/e Facilitator's Guide. San Francisco.

33. Kouzes JM, Posner BZ (2016) Learning Leadership: The Five Fundamentals of Becoming an Exemplary Leader. John Wiley \& Sons.

34. Posner BZ, Kouzes JM (1988) Relating leadership and credibility. Psychological reports 63: 527-530.

35. Stoner CR, Stoner J (2012) Building Leaders: Paving the path for emerging leaders. Routledge.

36. Waite R, McKinney N, Smith-Glasgow ME, Meloy FA (2014) The embodiment of authentic leadership. Journal of Professional Nursing 30: 282-291.

37. Sloan J (2016) Learning to think strategically. Routledge.

38. Griffiths K, Campbell M (2009) Discovering, applying and integrating: The process of learning in coaching. International Journal of Evidence Based coaching and mentoring $7: 16-30$.

39. Joo BKB, Sushko JS, McLean GN (2012) Multiple faces of coaching: Manager-as-coach, executive coaching, and formal mentoring. Organization Development Journal 30: 19.

40. De Vries MFK, Korotov K (2007) Creating transformational executive education programs. Academy of Management Learning \& Education 6: 375-387.

41. Henein A, Morissette F (2009) Made in Canada Leadership: Wisdom from the Nation's Best and Brightest on the Art and Practice of Leadership. John Wiley \& Sons.

42. Kanter RM (1990) When giants learn to dance. Simon and Schuster.

43. Fullerton JT, Lantz J, Quayhagen MP (1992) The level and focus of geriatric nursing content in ADN and BSN programs. Journal of Nursing Education 31 390-396.

44. Maclntyre P (2014) A quantitative correlational research study of leadership development for women engineers.

45. Barnhart G (2012) Physician Whiplash. Trustee 65: 33-34.

46. Tuleja EA (2014) Developing cultural intelligence for global leadership through mindfulness. Journal of Teaching in International Business 25: 5-24.

47. Loehr J (2008) The power of story: change your story, change your destiny in business and in life. Simon and Schuster.

48. Melina LR, Burgess GJ, Lid-Falkman L, Marturano A (2013) The Embodiment of Leadership: A Volume in the International Leadership Series, Building Leadership Bridges. John Wiley \& Sons.
49. Brookfield S (1995) The getting of wisdom: What critically reflective teaching is and why it's important. Becoming a critically reflective teacher, $\mathrm{pp}: 1-28$

50. Densten IL, Gray JH (2001) Leadership development and reflection: what is the connection?. International Journal of Educational Management 15: 119-124.

51. Cunliffe AL (2009) The philosopher leader: On relationalism, ethics and reflexivity-A critical perspective to teaching leadership. Management Learning 40: 87-101.

52. Hannum KN, Martineau JW, Reinalt C (2007) The handbook of leadership development evaluation. San Francisco.

53. Garcia EJ (2010) MBA lecturers' curriculum interests in leadership. Management learning 41: 21-36.

54. Garcia EJ (2009) Raising leadership criticality in MBAs. Higher education 58 113-130.

55. De Haan E, Bertie C, Day A, Sills C (2010) Clients' Critical Moments of Coaching: Toward a "Client Model" of Executive Coaching. Academy of Management Learning \& Education 9: 607-621.

56. De Haan E, Duckworth A (2013) Signalling a new trend in executive coaching outcome research. International Coaching Psychology Review 8: 6-19.

57. Duckworth A, De Haan E, Birch D, Hardman P, Jones C (2010) Executive Coaching Outcome Research: The Predictive Value of Common Factors such as Relationship, Personality Match and Self-Efficacy. Consulting Psychology Journal: Practice and Research.

58. Bajramovic H, LeMay PH (2015) Primal Games: Why We Do What We Do. Parzival press.

59. Ibarra H, Hansen MT (2011) Are you a collaborative leader? Harvard business review 89: 68-74.

60. Fairman JC, Mackenzie SV (2012) Spheres of teacher leadership action for learning. Professional development in education 38: 229-246.

61. Dinolfo S, Silva C, Carter NM (2012) High Potentials in the Pipeline: Leaders Pay It Forward. New York, USA.

62. Fields DL, Herold DM (1997) Using the leadership practices inventory to measure transformational and transactional leadership. Educational and Psychological Measurement 57: 569-579.

63. Carless SA (2001) Assessing the discriminant validity of the Leadership Practices Inventory. Journal of Occupational and Organizational Psychology 74: 233-239.

64. Herold DM, Fields DL (2004) Making sense of subordinate feedback for leadership development confounding effects of job role and organizational rewards. Group \& Organization Management 29: 686-703.

65. Vito GF, Higgins GE (2010) Examining the validity of the leadership challenge inventory: the case for law enforcement. International Journal of Police Science \& Management 12: 305-319.

66. Clavelle JT, Drenkard K, Tullai-McGuinness S, Fitzpatrick JJ (2012) Transformational leadership practices of chief nursing officers in Magnet $\circledast$ organizations. Journal of Nursing Administration 42: 195-201.

67. Duygulu S, Kublay G (2011) Transformational leadership training programme for charge nurses. Journal of advanced nursing 67: 633-642.

68. Foli KJ, Braswell M, Kirkpatrick J, Lim E (2014) Development of Leadership Behaviours in Undergraduate Nursing Students: A Service-Learning Approach. Nursing education perspectives 35: 76-82.

69. Tourangeau AE, McGilton K (2004) Measuring leadership practices of nurses using the leadership practices inventory. Nursing Research 53: 182-189.

70. Posner B (2010) Leadership practices inventory (LPI) data analysis

71. Jandaghi G, Matin HZ, Farjami A (2009) Comparing transformational leadership in successful and unsuccessful companies. African Journal of Business Management 3: 272

72. Barakett J, Cleghorn A (2000) Sociology of education: An introductory view from Canada. Scarborough, Ont: Prentice Hall Allyn and Bacon Canada.

73. Bower KM, DSL P (2012) Leadership coaching: Does it really provide value. Journal of Practical Consulting 4: 1-5. 
Citation: MacIntyre PL, Souvestre PA (2017) Building Global Leadership to Optimize the Future of Traditional and Alternative Medicine. J Health Educ Res Dev 5: 208. doi: 10.4172/2380-5439.1000208

Page 10 of 11

74. Bowles S, Cunningham CJ, De La Rosa GM, Picano J (2007) Coaching leaders in middle and executive management: Goals, performance, buy-in. Leadership \& Organization Development Journal 28: 388-408.

75. Burns JM (2005) Leadership. Leadership 1: 11-12.

76. Capozzi MM, Dye R, Howe A (2011) Sparking creativity in teams: An executive's guide. McKinsey Quarterly, p: 2

77. Walker G, Collins J (2006) Good to Great: Why Some Companies Make the Leap: And Others Don't.

78. Covey SM (2006) The speed of trust: The one thing that changes everything Simon and Schuster.

79. Cerni T, Curtis GJ, Colmar SH (2010) Executive coaching can enhance transformational leadership. International Coaching Psychology Review 5: 81-85

80. Nohria N, Khurana R (2013) Handbook of leadership theory and practice: An HBS centennial colloquium on advancing leadership. Harvard Business Press.

81. Fralicx, R, Dixon R (2012) Transformation from the top. Trustee: the journal for hospital governing boards 65: 23

82. D'Aprix R (2008) The Credible Company: Communicating with a Skeptical Workforce. John Wiley \& Sons.

83. Davidson R (2007) "Brain Scans Show Meditation Changes Minds Increases Attention".

84. Emes RD, Pocklington AJ, Anderson CN, Bayes A, Collins MO, et al. (2008) Evolutionary expansion and anatomical specialization of synapse proteome complexity. Nature neuroscience 11: 799-806.

85. Ericsson KA (2006) The influence of experience and deliberate practice on the development of superior expert performance. The Cambridge handbook of expertise and expert performance 38: 685-705.

86. Ericsson KA, Prietula MJ, Cokely ET (2007) The making of an expert. Harvard business review 85: 114 .

87. Goleman D (1996) Emotional Intelligence. Why It Can Matter More than IQ. Learning 24: 49-50.

88. Goleman D (2003) Destructive Emotions: How Can We Overcome Them? A Scientific Dialogue with the Dalai Lama by Daniel Goleman, New York, USA.

89. Hernez-Broome G (2012) Social intelligence: the new science of human relationships.

90. Goleman D, Boyatzis R (2008) Social intelligence and the biology of leadership Harvard business review 86: 74-81.

91. Goleman D (2008) An Evening with Daniel Goleman, Canada.

92. Grewal D (2012) How wealth reduces compassion: As riches grow, empathy for others seems to decline. Scientific American.

93. Haghighi K, Smith KA, Olds BM, Fortenberry N, Bond S (2008) The time is now: Are we ready for our role. Journal of Engineering Education 97: 119-121.

94. Rada-Florina H, Simona S, Rita-Monica T, Michaela RC (2012) About emotiona intelligence and leadership. Annals of Faculty of Economics 1: 744-749.

95. Hughes RL (1993) Leadership: Enhancing the lessons of experience. Richard D Irwin Inc, 1333 Burridge Parkway, Burridge, IL 60521.

96. lacoboni M, Molnar-Szakacs I, Gallese V, Buccino G, Mazziotta JC, et al (2005) Grasping the intentions of others with one's own mirror neuron system. PLoS Biol 3: e79.

97. Khattak H, Ku H, Goh S (2012) Courses for teaching leadership capacity in professional engineering degrees in Australia and Europe. European Journal of Engineering Education 37: 279-296.

98. Canadian Nurses Association (2005) Nursing leadership development in Canada. Canadian Nurses Association, Ottawa.

99. Madsen SR, Ngunjiri FW (2015) Women as Global Leaders. European Business Review.

100. Keim B (2009) "Cooperation Beats Selfishness, at Least in Theory", Wired Science.

101. Koechlin E, Charron S (2010) Multitasking Splits the Brain. Science Magazine.
102. Ladhani Z, Shah $\mathrm{H}$, Wells R, Friedman S, Bezuidenhout J, et al. (2015) Global leadership model for health professionals - A case study of the FAIMER program. Journal of Leadership Education, pp: 67-91.

103. Lehrer J (2008) The mirror neuron revolution: Explaining what makes humans social.

104. Levenson A (2009) Measuring and maximizing the business impact of executive coaching. Consulting Psychology Journal: Practice and Research 61: 103

105. Mathews J (2016) Toward a conceptual model of global leadership. IUP Journal of Organizational Behavior 15: 38

106. MacLeod L (2016) Listening: more than what meets the ear. Physician Leadership Journal 3: 14-20.

107. McKenna PJ, Maister DH (2002) First among equals: how to manage a group of professionals. Simon and Schuster.

108. Mendenhall ME (2006) The elusive, yet critical challenge of developing global leaders. European Management Journal 24: 422-429.

109. Mosher D (2009) The Power of the Present Moment. Science of Mind Magazine 8: 4-7.

110. Newton C (2004) Meditation and the Brain: New imaging technology makes it possible for scientists to document the brain activity of Buddhist monks. Technology Review.

111. Ng KY, Van Dyne L, Ang S (2009) From experience to experiential learning: Cultural intelligence as a learning capability for global leader development. Academy of Management Learning \& Education 8: 511-526.

112. Oddou GR, Mendenhall ME (2008) Global leadership development. Global leadership: Research, practice and development, pp: 160-174.

113. Osland JS, Bird A, Mendenhall M, Osland A (2006) 11 Developing global leadership capabilities and global mindset: a review. Handbook of research in international human resource management, p: 197

114. Posner BZ (2013) It's how leaders behave that matters, not where they are from. Leadership \& organization development journal 34: 573-587.

115. Posner BZ, Westwood RI (1995) A cross-cultural investigation of the shared values relationship. International Journal of Value-Based Management 8 : 197-206.

116. Reeve DW (2010) There is an urgent need for engineering leadership education. Engineering Leadership Review 1: 1-6.

117. Saltzman W, Maestripieri D (2011) The neuroendocrinology of primate maternal behavior. Progress in Neuro-Psychopharmacology and Biological Psychiatry 35: 1192-1204.

118. Santella A (2007) All the Rage: Why everyone is so angry and why we mus calm down. Utne Reader, Ogden Publications, pp: 36-41.

119. Schein EH (2009) The corporate culture survival guide. John Wiley \& Sons p: 158

120. Schein EH (2010) Organizational culture and leadership. John Wiley \& Sons, p: 2.

121. Seligman ME (2012) Flourish: A visionary new understanding of happiness and well-being. Simon and Schuster, New York, USA.

122. Skloot $R$ (2007) Why is it so damn hard to change. The Oprah Magazine 8 163-166.

123. Steers RM, Sanchez-Runde C, Nardon L (2012) Leadership in a global context: New directions in research and theory development. Journal of World Business 47: 479-482.

124. Sweeney PJ, Thompson V, Blanton H (2009) Trust and Infleunce in Combat: An Interdependent Model. Journal of Applied Social Psychology 39: 235-264.

125. Steven Terrell R, Rosenbusch K (2013) How global leaders develop. Journal of Management Development 32: 1056-1079.

126. Thach EC (2002) The impact of executive coaching and 360 feedback on leadership effectiveness. Leadership \& Organization Development Journal 23: $205-214$.

127. Turesky EF, Gallagher D (2011) Know thyself: Coaching for leadership using Kolb's experiential learning theory. The Coaching Psychologist 7: 5-14. 
Citation: Maclntyre PL, Souvestre PA (2017) Building Global Leadership to Optimize the Future of Traditional and Alternative Medicine. J Health Educ Res Dev 5: 208. doi: 10.4172/2380-5439.1000208

Page 11 of 11

128. Von Bertalanffy L (1973) The meaning of general system theory. General system theory: Foundations, development, applications, pp: 30-53.

129. VanderPal G (2014) Global leadership, IQ and global quotient. Journal of Management Policy and Practice 15: 120.

130. Waldman DA, Ramirez GG, House RJ, Puranam P (2001) Does leadership matter? CEO leadership attributes and profitability under conditions of perceived environmental uncertainty. Academy of management journal 44 134-143.

131. Wamsley EJ, Tucker M, Payne JD, Benavides JA, Stickgold R (2010) Dreaming of a learning task is associated with enhanced sleep-dependent memory consolidation. Current Biology 20: 850-855. 